\title{
Gut Microbiota and Colorectal Cancer
}

\author{
Ya-Nan Yu ${ }^{a}$ Jing-Yuan Fang ${ }^{b, c}, d$ \\ a Department of Gastroenterology, The Affiliated Hospital of Qingdao University, Qingdao, \\ and ${ }^{b}$ Division of Gastroenterology and Hepatology, Renji Hospital, Shanghai Jiao-Tong \\ University School of Medicine, Shanghai Institute of Digestive Disease, 'Key Laboratory \\ of Gastroenterology and Hepatology, Ministry of Health, and dState Key Laboratory of \\ Oncogene and Related Genes, Shanghai, China
}

\section{Key Words}

'Alpha-bug' model · Colorectal cancer · 'Driver-passenger' model · Gut microbiota · 'Intestinal microbiota adaptions' model

\begin{abstract}
Background: Colorectal cancer (CRC) is a leading cause of cancer-related mortality worldwide whose incidence has increased rapidly in recent years. There is growing evidence that the complex gut microbiota community plays an important role in the development of intestinal tumorigenesis. Summary: This review aimed to explore the correlation between gut microbiota and CRC as well as to identify the pathogens and their metabolites that affect CRC and the potential models of gut microbiota action. It promotes our understanding of the correlation between gut microbiota and CRC. Key Message: Our knowledge of the risk factors associated with gut microbiota for CRC development, as well as of the mechanism how intestinal bacteria act on colorectal tumorigenesis, has improved, leading to a better understanding of the correlation between gut microbiota and CRC. Practical Implications: The intestinal microbiota community has a close relationship with CRC by influencing the mechanism of the body and by regulating the physiological function of the colorectum and even the entire digestive system. Gut microbiota have been linked to CRC based upon their toxic and genotoxic metabolites production by fermentation of dietary ingredients. These metabolites could bind specific intestinal cell surface receptors and subsequently affect intracellular signal transduction. The mechanisms by which gut microbiota affect CRC development include the 'Alpha-bug' model, the 'driver-passenger' model and the 'intestinal microbiota adaptions' model. This review promotes our understanding of the correlation between gut microbiota and CRC.




\section{Introduction}

Colorectal cancer (CRC) is a leading cause of cancer-related mortality worldwide whose incidence has increased rapidly in recent years [1]. It is often the case that complex causes lead to malignant tumorigenesis. Infectious agents, such as bacteria or viruses, are associated with several types of cancer [2]. These cancers tend to have a high level of exposure to microbes in tissues. Several direct associations between microbes and cancer have ben identified over the past 30 years, including Helicobacter pylori and gastric cancer, human papillomavirus and cervical cancer, or hepatitis B virus and liver cancer $[3,4]$. There is growing evidence that the complex gut microbiota community plays an important role in the development of intestinal tumorigenesis [5-8]. In this review, we will explore the risk factors associated with gut microbiota in the development of CRC, as well as the relationship between gut microbiota and CRC.

\section{Overview of Human Gut Microbiota}

There are about 100 trillion bacteria in the human intestine, of varying and elaborate structures, which constitute the intestinal microbiome [9]. The human gut microbiota are dominated by facultative anaerobes, including Lactobacilli, Enterococci, Streptococci and Enterobacteriaceae, and by strict anaerobes, including Bacteroides, Eubacterium, Bifidobacterium, Fusobacterium, Peptostreptococcus and Atopobium [10]. There are more than 500 different species that may be present in the commensal microbiota of normal intestines [11]. This large group of bacteria are referred to as intestinal symbiotic bacteria, because of their mutualistic and interdependent relationship with the human body during the long period of co-evolution [12].

Some specific strains of bacteria have been classified as pathogens for cancer, such as Streptococcus bovis, H. pylori, Fusobacterium nucleatum and Enterococcus faecalis [2, 13-16]. In addition, some strains of bacteria, including Lactobacillus acidophilus and Bifidobacterium longum, may inhibit colorectal tumorigenesis $[17,18]$. The intestinal microbiota community has a close relationship with CRC by both influencing mechanism of the body and regulating the physiological function of the colorectum and even the entire digestive system $[12,19]$.

\section{Gut Microbiota and Their Metabolites in the Promotion of CRC}

Gut microbiota have been linked to CRC based upon their toxic and genotoxic metabolites production by fermentation of dietary ingredients. These metabolites could bind specific intestinal cell surface receptors and subsequently affect intracellular signal transduction.

\section{Enterotoxigenic Bacteroides fragilis}

Enterotoxigenic Bacteroides fragilis (ETBF) acts during the initiation phase of CRC by producing $B$. fragilis toxin [20]. In addition to its direct genotoxic effect, $B$. fragilis toxin stimulates intestinal epithelial cell shedding and gamma-secretase-dependent E-cadherin cleavage [21]. This cleavage increases the permeability of the intestinal barrier and triggers $\beta$-catenin/Wnt signaling transduction in intestinal epithelial cells, which contributes to the proliferation and oncogenic transformation of CRC [22]. ETBF triggers colitis and induces colon tumorigenesis in multiple intestinal neoplasia (Min) mice via activation of signal transducer and activator of transcription 3 (STAT3) and T helper type $17 \mathrm{~T}$ cell responses [23]. 


\section{Sulfate-Reducing Bacteria}

Sulfate-reducing bacteria are anaerobic microorganisms that can obtain energy by oxidizing organic compounds or molecular hydrogen $\left(\mathrm{H}_{2}\right)$ while reducing sulfate $\left(\mathrm{SO}_{4}^{2-}\right)$ to hydrogen sulfide $\left(\mathrm{H}_{2} \mathrm{~S}\right)$. These organisms 'breathe' sulfate rather than oxygen in a form of anaerobic respiration. The sulfate-reducing bacteria mainly consist of the Deltaproteobacteria, including the orders of sulfate-reducing bacteria, including Desulfobacterales, Desulfovibrionales and Syntrophobacterales, which account for the largest group of sulfate-reducing bacteria [24]. The second largest group is found among the Firmicutes, including the genera Desulfotomaculum, Desulfosporomusa and Desulfosporosinus. Other studies have shown that $\mathrm{H}_{2} \mathrm{~S}$ produced by sulfate-reducing bacteria is toxic to intestinal epithelium cells [25]. Further, Attene-Ramos et al. [26] found that even low concentrations of $\mathrm{H}_{2} \mathrm{~S}$ can cause significant DNA damage in human cells.

\section{Fusobacterium nucleatum}

In 2012, F. nucleatum was identified as a potential pathogen of CRC in an analysis of the gut microbial structures of CRC tissues versus matched normal tissues from the same subject $[2,16]$. A dominant enrichment of Fusobacterium spp. sequences associated with CRC tissues has been observed, using $16 \mathrm{~S}$ rDNA and metagenomic analyses. Fusobacterium spp. act as invasive anaerobes in oral infections as well as in appendicitis and inflammatory bowel disease [16,27]. Recent studies have provided experimental support for F. nucleatummediated induction of colonic tumorigenesis. Apc(Min/+) mice showed a significant increase in colon and small bowel tumors after continuous exposure to F. nucleatum [28]. Data revealed that $F$. nucleatum could change the tumor microenvironment of colonic tumors, inducing an increase in myeloid-derived immune cells and upregulating inflammation-associated genes. The data also showed a gradient abundance of $F$. nucleatum in feces among healthy and tumor patients. These results suggested that Fusobacterium detection might not be a sufficient biomarker for identifying patients at high risk of CRC [28, 29].

\section{Reactive Oxygen Intermediates}

Reactive oxygen intermediates are chemically reactive molecules containing oxygen, including often superoxide, hydrogen peroxide, hypochlorous acid, singlet oxygen and hydroxyl free radicals. Growing evidence suggests that reactive oxygen intermediates play a part in the development of CRC by inducing oxidative DNA damage [30]. Huycke et al. [31] observed that the intestinal symbiotic bacterium E. faecalis produced extracellular superoxide and hydrogen peroxide, leading to intestinal epithelial cell DNA damage in vivo and in vitro. E. faecalis also demonstrated the ability to induce dysplasia and carcinoma in IL-10 $10^{-/}$ mice, results that could not be observed in germ-free mice [32]. Based on these studies, we speculate that reactive oxygen intermediates play an important role in CRC by inducing colonic epithelial cell DNA damage in the process of inflammation.

\section{Bile Acid and Secondary Bile Acid}

Gut microbiota play an important role in the metabolism of bile acid in human intestines. Certain bacteria transform bile acid to secondary bile acid via $7 \alpha$-dehydroxylation [33]. Secondary bile acids, especially deoxycholic acid (DCA), are thought to be genotoxic, having the effect of promoting colon tumorigenesis [34]. DCA caused intestinal epithelium DNA damage that might lead to apoptosis, and triggered apoptosis in a p53-independent manner [35]. Many studies have proved that DCA is associated with CRC: high concentrations of fecal DCA increase the risk of CRC [36]. 


\section{How Do Gut Microbiota Affect the Development of CRC?}

\section{The 'Alpha-Bug' Model}

Sears and colleagues $[23,37]$ proposed the 'Alpha-bug' model after clarifying the capacity of ETBF to induce colonic tumors in Min mice. The 'Alpha-bug' hypothesis integrates the single intestinal bacteria and gut microbiome community views of microbial tumorigenesis. 'Alpha-bugs' was defined as certain intestinal commensal bacteria that produce epithelium gene mutations directly as well as indirectly.

ETBF rapidly triggers the exclusive activation of STAT3, which is a member of a family of transcription factors mediating $\mathrm{T}$ cell lineage development, serving as key regulators of tumorigenesis [38]. Additionally, STAT3 activation is required for the induction of Th17 immune responses, which might promote cancer in cooperation with the modified colonic epithelium [23]. This model suggests that ETBF promotes colonic tumorigenesis by modifying the epithelium and mucosa immune function as well as the intestinal microenvironment. The modification of the colon epithelium includes the activation of certain signal transduction pathways [38-40], and epithelium DNA damage, which promotes CRC through releasing the toxin by ETBF [41] or the release of reactive oxygen intermediates by inflammatory cells [42].

'Alpha-bugs' bacteria may enhance carcinogenesis by their permanent presence and by selective 'crowding out' of cancer-protective intestinal bacteria. There are several candidate 'Alpha-bugs', including ETBF, Streptococcus gallolyticus (also known as S. bovis), superoxideproducing E. faecalis and Escherichia coli [31,43-45].

\section{The 'Driver-Passenger' Model}

Recently, high-throughput sequencing technology has allowed us to explore the gut microbial structures of healthy and diseased body sites. Several experimental data sets support a possible role for gut microbiota in CRC $[2,7,16,46]$. Based on this, Tjalsma et al. [47] firstly proposed a bacterial counterpart of the genetic 'driver-passenger' model of CRC, which will be incorporated into the genetic paradigm of CRC progression. The 'driverpassenger' model is different from the 'Alpha-bug' model. The 'driver-passenger' model suggests that 'driver' bacteria initiate CRC and that these 'driver' bacteria are then replaced by 'passenger' bacteria; either one can promote CRC development. First, certain intestinal symbiotic bacteria drive epithelium cell DNA damage (termed bacterial drivers). Second, colorectal tumorigenesis is mediated by alterations to the intestinal microenvironment, which are conducive to the proliferation of certain opportunistic pathogens or probiotics (termed bacterial passengers) [47], such as Fusobacterium spp. [2, 16], S. bovis [48, 49] and Roseburia spp. [46].

To summarize, bacteria of the 'driver-passenger' model have distinct roles in CRC and imply differences in their temporal association with the colonic mucosa. This correlates with alterations of gut microenvironment during CRC progress. Furthermore, recent studies of gut microbiota reported the higher and lower representation of certain bacteria in tumor tissue, stating that although bacteria drivers are underrepresented, they may be present in low, but sufficient, abundance. The colonization of bacteria drivers in tumor tissue is likely to depend on strain-specific virulence characteristics. The propensity for colonization may depend on the specific genotype and expression profile of certain strains.

\section{The 'Intestinal Microbiota Adaptions' Model}

The development of CRC results through a lengthy process from normal tissue to hyperplasia, adenoma and, eventually, carcinoma [50]. During this process, the intestinal microbiota maintain a dynamic balance, termed 'adaptions' [51]. 'Intestinal microbiota adaptions' is dependent on the stability and resilience of the human gut microbiota [52]. Resilience is 
the amount of stress or disturbance that can be tolerated before a system is modified towards a different equilibrium state [52].

Under healthy conditions, gut microbiota maintain homeostasis with the human body and the intestinal microenvironment. This balance may be disrupted if the microbiota microenvironment is stimulated by factors in vivo or in vitro. The composition of the gut microbiota becomes modified according to the host's physiological state. Factors including heredity, diet and environment contribute to the function of pathogens, inducing CRC occurrence. At the same time, the growth of a tumor leads to changes in the intestinal mucosal barrier function and local tumorigenesis microenvironment, which are conducive to shifting the equilibrium state of the intestinal microenvironment. Some bacteria will thrive in the new intestinal microenvironment, while other bacteria unsuitable for survival decrease or even disappear, reflecting the fact that gut microbiota are affected by the occurrence of CRC. Despite highly diverse intestinal microbiota composition, the core functional profiles are quite similar in different subjects. When cancer-promoting bacteria are dominant, the environment will be conducive to the occurrence and development of CRC; in contrast, when cancer-inhibiting bacteria are dominant, colorectal tumorigenesis will be blocked [47]. However, more research is required to reveal the correlation between changes in the intestinal microenvironment and microbiota homeostasis.

\section{Conclusions}

Over the last decades, CRC as a common, deadly human disease has been a hot topic in both preclinical and clinical medicine studies. Several clinical studies and experimental models have linked the gut microbiota with the occurrence of CRC. Gut microbiota may play a role in CRC development by influencing the body's mechanism and by regulating the physiological function of the colorectum and even the entire digestive system. Therefore, further studies are needed to determine the association of the gut microbiota and the host immune system with CRC tumorigenesis. This will lead to a deeper understanding of the mechanism of the gut microbiota's effect on CRC and the shift in microbiota homeostasis under the influence of tumors.

\section{References}

1 Uhry Z, Belot A, Colonna M, Bossard N, Rogel A, Iwaz J, Mitton N, Grosclaude P, Remontet L: National cancer incidence is estimated using the incidence/mortality ratio in countries with local incidence data: is this estimation correct? Cancer Epidemiol 2013;37:270-277.

2 Kostic AD, Gevers D, Pedamallu CS, Michaud M, Duke F, Earl AM, Ojesina AI, Jung J, Bass AJ, Tabernero J, Baselga J, Liu C, Shivdasani RA, Ogino S, Birren BW, Huttenhower C, Garrett WS, Meyerson M: Genomic analysis identifies association of Fusobacterium with colorectal carcinoma. Genome Res 2012;22:292-298.

3 Zur Hausen H: The search for infectious causes of human cancers: where and why. Virology 2009;392:1-10.

4 Warren JR: Helicobacter: the ease and difficulty of a new discovery (Nobel lecture). ChemMedChem 2006;1: 672-685.

5 Rowland IR: The role of the gastrointestinal microbiota in colorectal cancer. Curr Pharm Des 2009;15:15241527.

6 Zhu Q, Gao R, Wu W, Qin H: The role of gut microbiota in the pathogenesis of colorectal cancer. Tumour Biol 2013;34:1285-1300.

7 Chen HM, Yu YN, Wang JL, Lin YW, Kong X, Yang CQ, Yang L, Liu ZJ, Yuan YZ, Liu F, Wu JX, Zhong L, Fang DC, Zou W, Fang J: Decreased dietary fiber intake and structural alteration of gut microbiota in patients with advanced colorectal adenoma. Am J Clin Nutr 2013;97:1044-1052.

8 Wang T, Cai G, Qiu Y, Fei N, Zhang M, Pang X, Jia W, Cai S, Zhao L: Structural segregation of gut microbiota between colorectal cancer patients and healthy volunteers. ISME J 2012;6:320-329.

9 Ley RE, Peterson DA, Gordon JI: Ecological and evolutionary forces shaping microbial diversity in the human intestine. Cell 2006;124:837-848. 
10 Tlaskalová-Hogenová H, Stepánková R, Hudcovic T, Tucková L, Cukrowska B, Lodinová-Zádníková R, Kozáková H, Rossmann P, Bártová J, Sokol D, Funda DP, Borovská D, Reháková Z, Sinkora J, Hofman J, Drastich P, Kokesová A: Commensal bacteria (normal microflora), mucosal immunity and chronic inflammatory and autoimmune diseases. Immunol Lett 2004;93:97-108.

11 Mai V: Dietary modification of the intestinal microbiota. Nutr Rev 2004;62:235-242.

12 Neish AS: Microbes in gastrointestinal health and disease. Gastroenterology 2009;136:65-80.

13 Gold JS, Bayar S, Salem RR: Association of Streptococcus bovis bacteremia with colonic neoplasia and extracolonic malignancy. Arch Surg 2004;139:760-765.

14 Peek RM Jr, Blaser MJ: Helicobacter pylori and gastrointestinal tract adenocarcinomas. Nat Rev Cancer 2002; 2:28-37.

15 Wang X, Yang Y, Moore DR, Nimmo SL, Lightfoot SA, Huycke MM: 4-hydroxy-2-nonenal mediates genotoxicity and bystander effects caused by Enterococcus faecalis-infected macrophages. Gastroenterology 2012;142: 543-551.e7.

16 Castellarin M, Warren RL, Freeman JD, Dreolini L, Krzywinski M, Strauss J, Barnes R, Watson P, Allen-Vercoe E, Moore RA, Holt RA: Fusobacterium nucleatum infection is prevalent in human colorectal carcinoma. Genome Res 2012;22:299-306.

17 McIntosh GH, Royle PJ, Playne MJ: A probiotic strain of L. acidophilus reduces DMH-induced large intestinal tumors in male Sprague-Dawley rats. Nutr Cancer 1999;35:153-159.

18 Rowland IR, Bearne CA, Fischer R, Pool-Zobel BL: The effect of lactulose on DNA damage induced by DMH in the colon of human flora-associated rats. Nutr Cancer 1996;26:37-47.

19 Sonnenberg GF, Artis D: Innate lymphoid cell interactions with microbiota: implications for intestinal health and disease. Immunity 2012;37:601-610.

20 Wu S, Shin J, Zhang G, Cohen M, Franco A, Sears CL: The Bacteroides fragilis toxin binds to a specific intestinal epithelial cell receptor. Infect Immun 2006;74:5382-5390.

21 Wu S, Rhee KJ, Zhang M, Franco A, Sears CL: Bacteroides fragilis toxin stimulates intestinal epithelial cel shedding and gamma-secretase-dependent E-cadherin cleavage. J Cell Sci 2007;120:1944-1952.

22 Wu S, Morin PJ, Maouyo D, Sears CL: Bacteroides fragilis enterotoxin induces c-Myc expression and cellular proliferation. Gastroenterology 2003;124:392-400.

23 Wu S, Rhee KJ, Albesiano E, Rabizadeh S, Wu X, Yen HR, Huso DL, Brancati FL, Wick E, McAllister F, Housseau F, Pardoll DM, Sears CL: A human colonic commensal promotes colon tumorigenesis via activation of T helper type $17 \mathrm{~T}$ cell responses. Nat Med 2009;15:1016-1022.

24 Muyzer G, Stams AJ: The ecology and biotechnology of sulphate-reducing bacteria. Nat Rev Microbiol 2008;6: 441-454.

25 Wallace JL: Hydrogen sulfide-releasing anti-inflammatory drugs. Trends Pharmacol Sci 2007;28:501-505.

26 Attene-Ramos MS, Wagner ED, Gaskins HR, Plewa MJ: Hydrogen sulfide induces direct radical-associated DNA damage. Mol Cancer Res 2007;5:455-459.

27 Strauss J, Kaplan GG, Beck PL, Rioux K, Panaccione R, Devinney R, Lynch T, Allen-Vercoe E: Invasive potential of gut mucosa-derived Fusobacterium nucleatum positively correlates with IBD status of the host. Inflamm Bowel Dis 2011;17:1971-1978.

28 Kostic AD, Chun E, Robertson L, Glickman JN, Gallini CA, Michaud M, Clancy TE, Chung DC, Lochhead P, Hold GL, El-Omar EM, Brenner D, Fuchs CS, Meyerson M, Garrett WS: Fusobacterium nucleatum potentiates intestinal tumorigenesis and modulates the tumor-immune microenvironment. Cell Host Microbe 2013;14:207215.

29 Sears CL, Garrett WS: Microbes, microbiota, and colon cancer. Cell Host Microbe 2014;15:317-328.

30 Owen RW, Spiegelhalder B, Bartsch H: Generation of reactive oxygen species by the faecal matrix. Gut 2000; 46:225-232.

31 Huycke MM, Abrams V, Moore DR: Enterococcus faecalis produces extracellular superoxide and hydrogen peroxide that damages colonic epithelial cell DNA. Carcinogenesis 2002;23:529-536.

32 Balish E, Warner T: Enterococcus faecalis induces inflammatory bowel disease in interleukin-10 knockout mice. Am J Pathol 2002;160:2253-2257.

33 Wells JE, Williams KB, Whitehead TR, Heuman DM, Hylemon PB: Development and application of a polymerase chain reaction assay for the detection and enumeration of bile acid 7 alpha-dehydroxylating bacteria in human feces. Clin Chim Acta 2003;331:127-134.

34 Rubin DC, Shaker A, Levin MS: Chronic intestinal inflammation: inflammatory bowel disease and colitis-associated colon cancer. Front Immunol 2012;3:107.

35 Powolny A, Xu J, Loo G: Deoxycholate induces DNA damage and apoptosis in human colon epithelial cells expressing either mutant or wild-type p53. Int J Biochem Cell Biol 2001;33:193-203.

36 Imray CH, Radley S, Davis A, Barker G, Hendrickse CW, Donovan IA, Lawson AM, Baker PR, Neoptolemos JP: Faecal unconjugated bile acids in patients with colorectal cancer or polyps. Gut 1992;33:1239-1245.

37 Sears CL, Pardoll DM: Perspective: alpha-bugs, their microbial partners, and the link to colon cancer. J Infect Dis 2011;203:306-311.

38 Yu H, Kortylewski M, Pardoll D: Crosstalk between cancer and immune cells: role of STAT3 in the tumour microenvironment. Nat Rev Immunol 2007;7:41-51.

39 Markowitz SD, Bertagnolli MM: Molecular origins of cancer: molecular basis of colorectal cancer. N Engl J Med 2009;361:2449-2460. 
40 Sears CL: Enterotoxigenic Bacteroides fragilis: a rogue among symbiotes. Clin Microbiol Rev 2009;22:349369, Table of Contents.

41 Goodwin AC, Destefano Shields CE, Wu S, Huso DL, Wu X, Murray-Stewart TR, Hacker-Prietz A, Rabizadeh S, Woster PM, Sears CL, Casero RA Jr: Polyamine catabolism contributes to enterotoxigenic Bacteroides fragilisinduced colon tumorigenesis. Proc Natl Acad Sci USA 2011;108:15354-15359.

42 Housseau F, Sears CL: Enterotoxigenic Bacteroides fragilis (ETBF)-mediated colitis in Min (Apc+/-) mice: a human commensal-based murine model of colon carcinogenesis. Cell Cycle 2010;9:3-5.

43 Herrera P, Kwon YM, Ricke SC: Ecology and pathogenicity of gastrointestinal Streptococcus bovis. Anaerobe 2009;15:44-54.

44 Martin HM, Campbell BJ, Hart CA, Mpofu C, Nayar M, Singh R, Englyst H, Williams HF, Rhodes JM: Enhanced Escherichia coli adherence and invasion in Crohn's disease and colon cancer. Gastroenterology 2004;127: 80-93.

45 Maddocks OD, Short AJ, Donnenberg MS, Bader S, Harrison DJ: Attaching and effacing Escherichia coli downregulate DNA mismatch repair protein in vitro and are associated with colorectal adenocarcinomas in humans. PLoS One 2009; 4:e5517.

46 Marchesi JR, Dutilh BE, Hall N, Peters WH, Roelofs R, Boleij A, Tjalsma H: Towards the human colorectal cancer microbiome. PLoS One 2011;6:e20447.

47 Tjalsma H, Boleij A, Marchesi JR, Dutilh BE: A bacterial driver-passenger model for colorectal cancer: beyond the usual suspects. Nat Rev Microbiol 2012;10:575-582.

48 Klein RS, Recco RA, Catalano MT, Edberg SC, Casey JI, Steigbigel NH: Association of Streptococcus bovis with carcinoma of the colon. N Engl J Med 1977;297:800-802.

49 Srivastava A, Walter N, Atkinson P: Streptococcus bovis infection of total hip arthroplasty in association with carcinoma of colon. J Surg Orthop Adv 2010;19:125-128.

50 Fearon ER: Molecular genetics of colorectal cancer. Annu Rev Pathol 2011;6:479-507.

51 Hooper LV, Macpherson AJ: Immune adaptations that maintain homeostasis with the intestinal microbiota. Nat Rev Immunol 2010;10:159-169.

52 Lozupone CA, Stombaugh JI, Gordon JI, Jansson JK, Knight R: Diversity, stability and resilience of the human gut microbiota. Nature 2012;489:220-230. 